\title{
Reflexões sobre a Geografia
}

\author{
Jean Dresch
}

p. $207-214$

\section{revista}

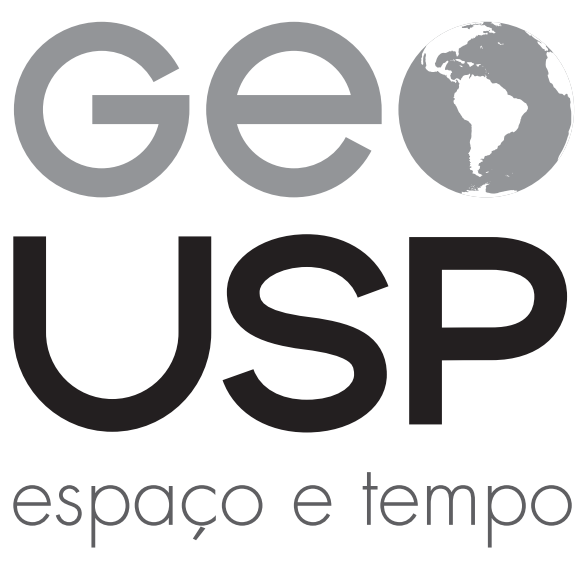

Volume $20 \bullet n^{\circ} 1(2016)$
Como citar:

DRESCH, J. Reflexões sobre a Geografia. Geousp - Espaço e Tempo (Online), v. 20, n. 1, p. 207-214, mês. 2016. ISSN 2179-0892.

Disponível em: http://www.revistas.usp.br/geousp/article/ view/114858. DOI: http://dx.doi.org/10.11606/issn.21790892.geousp.2016.114858.

\section{(c) $(1) \Theta$}

Este artigo está licenciado sob a Creative Commons Attribution 4.0 License. 


\section{Reflexões sobre a geografia}

A geografia é uma ciência - pouco importa no momento o sentido que se atribua ao termo - a um tempo bastante antiga e muito recente.

Desde a Antiguidade, os pesquisadores adotaram o método de descrever e, em menor grau, de explicar, a ocorrência dos fenômenos físicos e humanos na superfície da Terra, cuja distribuição de influências recíprocas forma um todo bastante complexo.

Mas, ainda que o próprio termo geografia seja em si mesmo muito antigo, a maior parte dos pesquisadores tem produzido "geografia" sem tentar uma definição e, muitas vezes, sem sabê-la.

Para que a geografia tivesse consciência de ser-em-si, foi necessário, depois da Renascença, que ocorressem os descobrimentos geográficos, a exploração progressiva do mundo, sua penetração pela diversidade da economia capitalista e pelas populações europeias, a divisão dos impérios coloniais e/ou estabelecimento de zonas de influência pelos Estados imperialistas, foi necessário a multiplicação e o aperfeiçoamento de "ciências auxiliares": ciências físicas (astronomia, meteorologia, geologia, biologia vegetal e animal), ciências humanas (etnografia, sociologia, demografia, economia política, história).

Embora tenha havido progresso, sua definição continuará sendo tardia. Fixemo-nos nos séculos XV ou XVI: malgrado o extraordinário aumento do campo de observação desencadeado pelas descobertas geográficas, tais acontecimentos deram origem a cartas geográficas pouco precisas, porém necessárias aos novos viajantes, ou então a descrições mais ou menos pitorescas.

O conquistador em busca de ouro, o comerciante em busca de gêneros preciosos, o missionário em busca de almas para converter, não se preocupavam em explorar cientificamente os espaços encontrados pelas descobertas geográficas; a "opinião" continuava indiferente, a menos que houvesse uma direção na propaganda dos pesquisadores.

O Eldorado foi um dos primeiros "slogans" da moderna propaganda, destinado a ganhar a confiança dos futuros colonos e, mais tarde, dos acionistas das sociedades por comandita ou das companhias coloniais.

O mercantilismo favoreceu muito pouco a pesquisa científica.

É por isso que a geografia dos séculos XVII e XVIII fica isolada do progresso das outras ciências físicas e humanas.

Este atraso diante das ciências físicas e naturais não se faz acompanhar da Revolução Industrial, do avanço da história e da economia política e do progresso que acompanha o destino da burguesia e do capitalismo liberal.

O aparecimento da geografia como ciência moderna data do século XIX, mais da segunda metade do que da primeira.

Por isso mesmo, Humboldt e Ritter são considerados fundadores.

O primeiro lançou as bases da geografia física, e o segundo, historiador e filósofo, ainda que de estatura científica menor, exerceu uma influência bem mais profunda. 
Sua volumosa obra Die Erdkunde im Verhältniss zur Natur und zur Geschichte des Menschen tem um título simbólico; a geografia tem uma ambição desmesurada: englobando todas as ciências da natureza e do homem, ela termina por segregar o próprio homem.

Com esse resultado, ela responde a uma ideologia necessariamente orientada.

Ritter procura o Raume, os espaços, de antigas construções regionais, os espaços vitais. Ritter engaja a geografia num caminho perigoso. Nascida não apenas durante a conquista, mas durante o triunfo da classe burguesa, a geografia foi pelos seus objetivos mais uma filosofia que uma ciência, filosofia que os geógrafos alemães e os historiadores utilizavam com fins políticos.

Assim, a geografia foi usada como um meio de propaganda nacional ou internacional, como arma de combate entre Estados e impérios, muito mais talvez do que a própria história.

Seja como for, a geografia sofre ainda as consequências da juventude e das condições sociais e políticas do seu desenvolvimento científico.

Devido à falta de métodos específicos, a geografia, talvez mais que qualquer outra ciência, sofre a influência das ideologias em curso, e a geografia humana mais do que a física.

Por isso, sua concepção como disciplina universal engloba todas as ciências da Terra e todas as ciências humanas, todas as ciências concretas do espaço.

A geografia física é igualmente geografia matemática, geofísica, meteorologia e climatologia, hidrografia, geologia e biogeografia; a geografia humana usa os conceitos da história, da economia política, da etnografia, da sociologia e da linguística, e, assim, a lista pode se alongar indefinidamente.

A geografia talvez seja, por isso mesmo, menos uma ciência particular do que um conjunto de sínteses múltiplas, um ponto de vista.

geógrafo deve ser superiormente inteligente, detentor de vasto cabedal de conhecimentos, informado do que ocorre no mundo da ciência.

Ainda que especialistas de horizontes limitados desprezem o saber do geógrafo, pela dúvida quanto a sua capacidade científica para vastas comparações, a geografia lança luz sobre as ciências da terra e do homem, constituindo-a como origem e fim de toda a ciência da Terra.

Esse homem de ideias gerais é, como Lyautey no Marrocos, capaz de tirar conclusões satisfatórias da "filosofia da coisa"... imperialista; ele não hesita em ser simultaneamente geólogo e historiador, botânico e economista, escalando todas as plataformas, para grande escândalo dos especialistas que o ignoram, isolando-o do grande público, que lhe vota desprezo.

Não se trata, pois, de um retrato dramático ou de uma caricatura. Muito pelo contrário, esta ambição universal de grandeza constitui para a geografia em si o seu charme.

Embora concebida nos tempos da Renascença, ela ultrapassa em muito as forças de um homem.

Um jovem geógrafo, candidato à especialização em geografia, deve doravante, de posse do seu estado civil, distinto da história, estar atento para ser interrogado sobre tudo.

Para tanto, deve ter essencialmente uma informação quase universal; numa palavra: uma sólida cultura geral.

Mas que tipo de cultura geral?

Aquela instituída pelo "academicismo burguês", cujos altos desígnios mais tarde são escarnecidos pelo sentimento de segurança material "primária"; ou a do burguês, bem garantida por diplomas de bicho-pensante objetivo e de vontade cética, pelo menos em aparência? 
Nem uma nem outra, ainda que, evidentemente, não deixem de ser comuns os exemplos de uma geografia "primária" ou de uma geografia do mundo para crianças, bastante em moda: - nos jornais diários quase sempre chamando a atenção para um ou outro ponto escolhido do globo.

A verdadeira geografia - universalista! - deve ter uma concepção um pouco mais séria. Conquanto não possa evitar o fato de ficar submersa pela massa de documentos que manipula.

"Quem muito atraca pouco ensaca", diz o velho provérbio.

Em decorrência de utilizar os resultados de ciências muito distintas, a geografia condena sua empresa ao fracasso.

A descrição geográfica abandona o lugar de enumeração dos fatos, escolhidos mais ou menos arbitrariamente, mais ou menos isolados no abstrato. Quantas monografias regionais não se reduzem a uma acumulação de dados, classificados segundo uma ordem estabelecida, conduzindo o leitor até a estrutura geológica e, de passagem, ao hábitat, ao relevo, à hidrografia, ao clima, à vegetação, ao povoamento, aos gêneros de vida, uma verdadeira série de tiradas em sequela!

Sua justaposição não passa de uma explicação, e toda explicação por vezes não passa de uma ginástica intelectual.

Dessa forma, o geógrafo apercebe-se do perigo. As teses recentes não passam de geografias enciclopédicas. Alguns especializam-se em geografia física, outros em geografia humana.

Em geografia física, uns especializam-se em geomorfologia, outros em hidrografia ou potamologia, outros em climatologia, outros ainda em geografia botânica. Em geografia Humana, uns estudam preferencialmente os problemas de povoamento ou gêneros de vida e certas questões econômicas; alguns orientam mesmo suas pesquisas exclusivamente para a estrutura agrária, o hábitat, as cidades ou a indústria.

Todos, sem dúvida, pretendem abraçar o todo e não admitem a hipótese de um esforço desmesurado.

Mas, de qualquer forma, pretendem fixar os limites da geografia, procedendo a uma delimitação do saber no território geográfico. A geografia deve inserir-se nas subdivisões administrativas do ensino universitário, embora tenha conquistado tardiamente seu lugar. Falta, apenas, legitimar-se. Do mesmo modo que um filósofo rotula-se de psicólogo, lógico, moralista, sociólogo ou metafísico, os geógrafos devem distinguir a geografia física, humana, econômica, agrícola, industrial, política, histórica, regional. Ainda recentemente, George deu-nos uma geografia social. Além do mais, muita coisa pode ser "rotulada" sob tal epíteto. Esse geógrafo atira-se aos arquivos de história e remete suas pesquisas ao século XVIII..., muito embora ele não seja um historiador; pode produzir uma pesquisa de geologia estrutural sem ser um geólogo. Pelo contrário, ele se defende, embora cada um procure isoladamente enriquecer uma terminologia da especialidade, como se à geografia faltasse a consciência de suas próprias medidas.

Nestas condições, deve-se colocar a geografia ao lado da ciência ou das letras? A geografia é ciência ou arte? Ela é uma ciência, ainda que tome emprestado seus métodos de outras ciências, nas quais busca apoio; isto é muito verdadeiro em geografia física, cujas demonstrações são rigorosas e que ela procura exprimir em fórmulas matemáticas e sistematizar em leis. 
Por outro lado, é arte na medida em que retira técnicas particulares, busca descrições vivas de imagens, cujas abordagens e ideias gerais confinam com a filosofia. Ela estabelece a transição entre ciências naturais e ciências humanas. Mas, na França, ela está do lado das letras. Sempre esteve desse lado, e tudo indica que lá vai ficar. A geografia de Elisée Reclus era puramente descritiva; quando a geografia obteve o direito de cidadania na universidade, foi quando obteve sua consagração extrema no fim do século XIX, por um historiador como Vidal de La Blache, designado como fundador da escola geográfica francesa.

Reduzida à expressão de geografia histórica, a geografia francesa afastou-se paulatinamente da história. Talvez na França mais que em outros países, em conformidade com os princípios estabelecidos por Ritter, o homem foi o resultado da obra geográfica. A geografia pode estudar a estrutura de uma montanha, os peneplanos, os terraços fluviais ou as formas glaciárias, embora quase sempre faça uma introdução à geografia humana, indicando no estudo do meio o lugar apropriado do homem. Quanto à introdução do melhor lugar para o homem, essa já é uma questão mais delicada, ultrapassado o tempo de adoção de um determinismo mecanicista infantil.

Esta reação contrária aos historiadores e sociólogos criou nos geógrafos contemporâneos uma tendência a considerar a preponderância dos fatores humanos sobre os físicos, do rito sobre a obrigação, encontrada nos camponeses tuaregues ou tedas. A geografia considera o homem livre até o absoluto em relação a seu meio.

Apesar disso, ainda persiste muita confusão e contradição.

Essas contradições explicam-se sem dúvida pela época de nascimento da geografia, quando as ideologias burguesas se mostravam decadentes e, especialmente, nossa universidade napoleônica fossilizada. Por mais brilhante que seja a geografia produzida na crise que atravessamos, não é menos verdade que toda a produção intelectual francesa se encontra no atoleiro.

Qualquer que seja a área considerada, seu domínio de explicação é imenso. Por isso, será lógico que o trabalho de pesquisa seja um trabalho de equipe; quer se trate de pesquisas gerais ou regionais, o manuseio de documentos deve ser coletivamente organizado. Isso está fora de questão. Contudo, segundo métodos caros aos intelectuais burgueses, especialmente franceses, cada pesquisador é dono de uma determinada tarefa individual, estando isolado de um caminho global.

Na verdade, não existe geografia aplicada; não existe nenhum organismo de pesquisa digno desse nome. Cada um tenta acumular por sua própria conta sua documentação pessoal, sonegando informações aos demais colegas, acusando-os de incompetência e ignorância.

geógrafo físico deve ter uma sólida formação em matemática, física, química e todas as ciências naturais. Mas, na França, ele é bacharel em grego, e não faz muito tempo era licenciado em História com uma dissertação em latim. 
Certos professores refazem sua instrução em péssimas condições, o que agrava ainda mais o futuro especialista.

Os geógrafos físicos limitam suas pesquisas à geomorfologia, campo no qual os geólogos franceses ainda não têm interesse.

Entretanto, deve-se reconhecer que trabalhos de maior importância científica foram produzidos pelos americanos e pelos alemães que lançaram as bases da moderna geomorfologia.

Foram estudadas as formas de erosão e acumulação sem haver uma cultura em física ou química suficiente para analisar a gênese dos fenômenos: houve uma grande demora para se chegar a acordo sobre se os fatores climáticos são um princípio correto para explicar o ciclo de erosão normal, normalidade que não é a mesma para os habitantes de países temperados.

Mas é sobretudo em geografia humana que as insuficiências se tornam mais graves. Adotou-se a metodologia do esfacelamento das especialidades. Instituiu-se o hábito de distinguir geografia humana de geografia econômica. A segunda reduz-se a uma análise suficientemente fastidiosa da produção, de uma enumeração de produtos e cifras, independentes dos produtores. Estuda-se minuciosamente o hábitat.

As cifras, as casas, a cidade, procedem de noções abstratas, mais ou menos isoladas da estrutura econômica, das técnicas de produção e de troca, das relações sociais. Faz-se a distinção mesmo em geografia política, como se o Estado e as fronteiras não passassem de construções abstratas da imagem do homem-cidadão, que a ideologia burguesa distingue do homem-privado, como se a vida dos grupos humanos não passasse de elementos indissociáveis.

A especialização deve evitar que o geógrafo se confunda como um amador superficial; mas acontece exatamente o contrário: na maior parte dos casos, o geógrafo dissimula o complexo profundo da realidade humana e desestimula a curiosidade do pesquisador.

A geografia acaba por sofrer os impulsos das ciências ditas conexas. Não existe em importância uma geografia política mais que uma geografia econômica ou social, ou mesmo histórica.

Há somente uma geografia humana, ligada à história, à economia, à sociologia, a todas as outras ciências humanas, o que constitui uma síntese especial, limitada por sua vez aos fenômenos atuais concretos.

Descrição total da vida dos grupos humanos, é uma explicação da sua ligação profunda com as outras ciências humanas.

E isto, naturalmente, faz com que certas interpretações sejam condicionadas pelas ideologias em curso.

Os exemplos podem ser multiplicados às dezenas. Se o campo e o campesinato estão na moda, e o estudo do campo europeu foi enriquecido com os trabalhos de Marc Bloch, enquanto um historiador como Soboul termina por aderir à moda. Mas, se tais estudos permitem compreender as formas atuais dos campos e cidades e sejam, por conseguinte, o do domínio do geógrafo, essas estruturas são, na Europa, relíquias; a vida agrária está ligada de modo concreto às estruturas econômicas atuais, embora certos aspectos sejam evidentes, como a repartição das propriedades e o tipo de exploração. Por outro lado, contudo, são mais complexas as relações a desvendar, como o papel dos demandistas ou das grandes empresas na organização 
do mercado, dos comerciantes de adubos ou de material, das companhias de seguro, não esquecendo da legislação em vigor, cujo papel essencial compatibiliza a rentabilidade da empresa agrícola, moldando em definitivo suas possibilidades de transformação.

O camponês, porém, continua inspirando uma simpatia fácil, porque está ligado à terra, à lavoura e ao ciclo das estações. Mas o que pensa o citadino de um operário?

Este último não representa mais que uma mão de obra, um ser abstrato, que se calcula pelo preço e pelos lucros que proporciona, que pode ser reduzido a um material de estatística.

E a própria empresa em que o operário trabalha é considerada outro ser abstrato que pode ser reduzido a cifras econômicas compostas de muitos operários...

A criatura é distinguida, mas o funcionamento da empresa é mal compreendido. Pode-se falar em concentração vertical e horizontal, mas essa questão isolada não explica a origem do capital da empresa e os laços mantidos com os grandes organismos comerciais, industriais e bancários, nacionais e transnacionais.

Evidentemente, tais aspectos permanecem ocultos.

A compreensão torna-se maior quando os aspectos são por demais evidentes, como os EUA e a questão do petróleo.

Assim, como compreender as transformações de nosso país, como compreender a vida humana dos países dependentes, coloniais ou neocoloniais, senão analisando as condições e as formas dessa mesma dependência? Como compreender a Argélia e a Tunísia sem Rotschild, Mirabaud e Mallet, o Marrocos sem o Banco de Paris e dos Países Baixos, a Indochina sem o Banco da Indochina, a África Ocidental sem as sociedades de comércio, as velhas colônias sem as sociedades açucareiras, para citar apenas alguns exemplos?

Já foi feita a descrição do indígena e de sua evolução, como do nosso camponês anteriormente; é uma tarefa fácil, ainda que envolva muita sensibilidade.

Porém, em sentido amplo, a obra colonial reduz-se a uma enfadonha enumeração de produtos e ferrovias.

Os capitais investidos e em que ramos são investidos, eis como geralmente se coloca a questão.

Mas isto faz parte da geografia? Para determinar, em última análise, a vida social nesses países dependentes, assim como a vida social dos europeus, é precioso sobretudo explicar.

Como interpretar doutro modo os meios e as técnicas de produção, a manutenção de antigas estruturas sociais ou a formação de novas categorias, detentoras de sua própria ideologia - enfim, as condições próprias de evolução dos grupos sociais e a vida política?

A geografia humana, por isso mesmo, conduz à sociologia e à política. Ela estuda as relíquias do passado, sem deixar pressenti-las como história, permitindo-se compreender o presente e o sentido de sua transformação.

Semelhante programa é difícil de realizar por duas razões. A primeira decorre das exigências de conhecimento do geógrafo, a outra da necessidade de se desembaraçar dos métodos e ideologias correntes na universidade.

Todo trabalho geográfico pressupõe um manuseio gigantesco de documentos variados.

Isso supõe igualmente uma remissão ao quadro de conceitos admitidos e um trabalho de pesquisa de material empírico, a fim de preencher as lacunas da documentação publicada. 
A consequência pode ser a abstenção: não seria melhor trabalhar desse modo do que lançar a público trabalhos incompletos? Pierre George teve a audácia de lançar uma série de livros de "vulgarização", na coleção Que sais-je?, intitulados Geografia social, Geografia agrícola, Geografia industrial, Economia dos Estados Unidos. De um livro a outro, percebe-se o sucesso.

Soboul disse muito bem o que pensava a respeito da geografia social. De minha parte, sou menos entusiasta para com P. George. Minha atitude é talvez mesmo mais de crítica do que de congratulação.

Antes de mais nada, a expressão geografia social é muito infeliz: como se fosse possível abstrair a sociedade da produção! Concessão sem dúvida involuntária ao idealismo filosófico, e quem sabe ao editor, mas de qualquer maneira difícil de justificar. E além do mais, o que nos ensina a geografia social? Que existem sociedades rurais tradicionais, sociedades europeias complexas, terras em experiências, os EUA e a URSS?

A geografia social não seria mais que a geografia tradicional dos gêneros de vida, isolados da estrutura econômica da sociedade capitalista, que deste modo permite a manutenção das formas tradicionais de economia e sociedade, espaços em movimentação que provocam o nascimento de formas novas de economia no capitalismo e, por vezes, a retomada de novas estruturas que não são simples "experiências"? Como compreender as formas de produção e as relações de produção, as estruturas sociais ditas tradicionais e suas transformações, fazendo abstração das condições modernas de produção e troca?

$\bigcirc$ fato limitado à descrição dificulta a questão de revelar os erros de detalhe, e as explicações ficam estabelecidas apenas nas aparências. Uma interpretação marxista não se satisfaz somente com o emprego de uma terminologia formal, como qualificador uma sociedade de "feudal" sem levar em conta as devidas explicações.

P. George não obteve vantagens maiores ao tentar desembaraçar-se dos quadros ideológicos tradicionais quando fez a análise da geografia agrícola e da geografia industrial.

Como explicar o espaço agrícola atual sem levar em conta os fatores técnicos e também os fatores econômicos próprios de uma produção do tipo capitalista, que determinou a ocupação agrícola do mundo, os tipos de produção de mercado de produtos agrícolas? $\bigcirc$ que é na verdade um camponês, e quais são os tipos atuais?

Como se mantêm as tradições nos velhos países agrícolas e em que medida estão elas ameaçadas? Como se exerce, nos países novos ou em países de agricultura indígena tradicional, o controle do mercado da produção como, por exemplo, o controle que a United Fruit ou a Unilever exercem sobre tais países? Na geografia industrial de George, dotada de categorias essencialmente descritivas, não causa maiores surpresas encontrar definições abstratas - por que a propósito da França? - em que faltam exemplos concretos de concentrações industriais, comerciais ou bancárias no plano regional nacional ou internacional, tudo isto com raras exceções? Os trustes japoneses apresentam constituição mais típica do que os americanos? Deve-se reconhecer, contudo, que quando P. George estuda a economia dos EUA, sua análise é mais séria e mais sólida. Mas a economia dos EUA, evidentemente, não está limitada às fronteiras da Confederação? Como separar a economia dos EUA da exportação de capitais, da conquista de mercados exteriores de matérias-primas ou da organização metódica de zonas de influência econômica? 
A economia nacional é inseparável da economia imperialista; as consequências da guerra fizeram-se sentir precisamente dentro deste quadro.

Estas críticas têm seu propósito. E esperam uma resposta. Sublinham a força de P. George e suas fraquezas. A tarefa é difícil. Resta saber como organizar, e bem, o trabalho geográfico. A geografia é uma ciência universal, é essa a sua razão de ser.

Não se trata de limitar nem de fragmentar o conhecimento. Mas devemos reconhecer que existe uma divisão ou corte entre a geografia física e a humana. Isto fez com que, grosso modo, os meios e os fins confundissem o homem. Não se trata de um erro completo, mas também não é o real verdadeiro. É um erro relativo em geografia geral e uma verdade relativamente à geografia regional.

A geografia física é um aspecto, um ponto de vista das ciências naturais. Seus métodos ainda estão em formação.

$\bigcirc$ homem pode ser um fator de evolução do relevo, de transformação da cobertura vegetal ou da geografia dos animais. Embora ele seja um fator não é um fim. Que importa ao homem que tal peneplanície seja pós-herciniana ou eógena, que tal garganta esteja superposta ou antecedente, que tal relevo de tipo jurássico ou apalachiano tenha evoluído sob um clima mais ou menos úmido ou árido?

$\bigcirc$ que lhe importa é a forma atual do relevo, duma alta montanha, mais ou menos aérea, dum platô, duma planície de erosão ou aluvial cujo solo e o subsolo sejam mais ou menos férteis: numa palavra, sua gênese. Deve-se, portanto, separar a geografia física da geografia humana, colocar uma na faculdade de ciências e outra na de letras? Semelhante atitude foi rotulada de "esquerdismo" na URSS? Em todo caso, seria melhor aceitar mais facilmente nossa classificação universitária. Em tal recinto, ainda se pode desconfiar de definições formais.

Pelo menos seria mais conveniente procurar especializar-se em geografia física ou humana do que continuar produzindo uma geografia medíocre.

A divisão deve ser feita não na geografia em si, mas na própria forma de pesquisa. Quanto à geografia humana, ela não deve isolar da história, sociologia ou economia. Por que um geógrafo não deve fazer uso da história na ocasião de uma pesquisa geográfica?

Por que um historiador não pode adotar um ponto de vista geográfico numa pesquisa histórica? Desde que se procura estudar os grupos humanos, os métodos de trabalho são os mesmos e a documentação idêntica. Desconfie-se sempre das terminologias limitativas e mais ainda das definições abstratas e formais. Mas, além da geografia física geral e da geografia humana geral, a geografia regional é uma síntese onde as duas geografias buscam apoio mútuo e são inseparáveis.

E se é difícil um único homem fazer tal síntese, pode-se lançar mão de grupos especializados de pesquisadores, trabalhando lado a lado, em equipe, agora que na geografia, como nas outras ciências, o progresso será cada vez menos o resultado do esforço de pesquisadores isolados. 